Environmental Biology of Fishes Vol. 15, No. 1, p. 14, 1986

(C) Dr W. Junk Publishers, Dordrecht.

\title{
Technique of making fish illustration 15: stippled drawings for scientific specimens
}

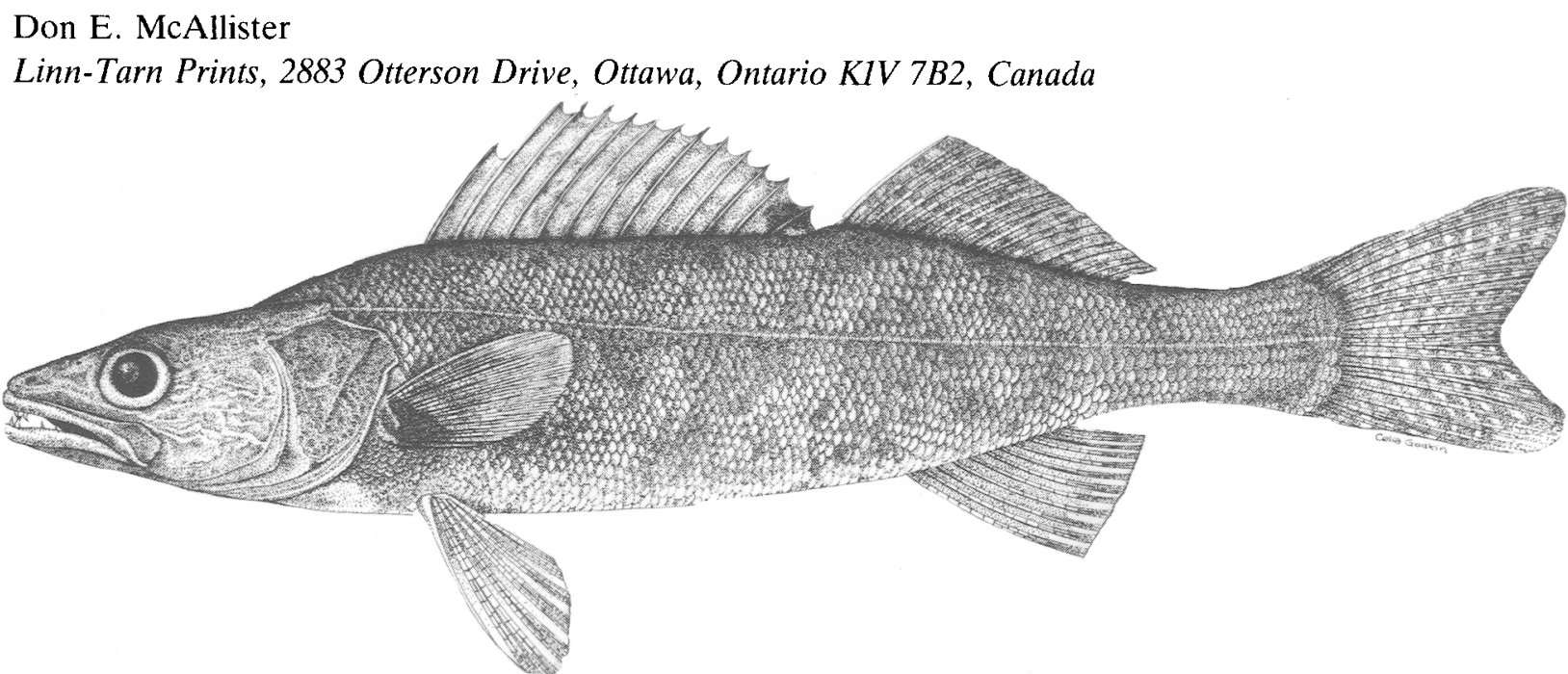

Bluc walleye, Stizostedion vitreum canadense Hubbs, 1926, Lake Erie at Port Crewe, Kent Co., Ontario. Specimen $440 \mathrm{~mm}$ SL. $650 \mathrm{~mm}$ TL $\sigma^{\top}, 0.6 \mathrm{~kg}$ (preserved). Drawing by Celia Godkin.

Technique: Stippling is a deceptively simple technique. The artist places dots on paper to show color patterns, translucency, reflections and shadowing. These effects are achieved mainly by variations in density of the stippling. However the effect can also be modified by randomness of stippling - the dots can be placed randomly, they can be deployed in straight or wavy lines, and they can be arranged in small clusters. Patterned spotting can be used to delineate structure such as scales or spines. But not only can the arrangement of the dots be varied, but the size and shape of the dots can be controlled. The graduation of shading over the back and sides from dark to light can be depicted by graduating the density of dots, or by decreasing the size of the dots. And macroand micromelanophores can be shown using different spot sizes and shapes.

Lines are often used in combination with stippling. The outline of the body may be shown by dense stippling or a pen line. Details of structure such as eye, jaws, and fins are often shown using lines.
The artist, Celia Godkin, born in England, living in Canada for 17 years, has an M.Sc. degree in ichthyology (Osteology \& phylogeny of the Congrogadidae), 7 years training as a natural science artist, and has been a professional natural science illustrator for 9 years (some concurrently). She is a co-ordinator of the Canadian GNSI Newsletter (GNSI = Guild of Natural Science Illustrators, Inc.). Celia has illustrated several books and new species of gobies and taught courses in illustration and nature drawing.

The species: The blue walleye, or blue pike as it was called by fishermen, occurred in Lake Erie (and possibly in Lake Ontario and the Niagara River) but became extinct due to overfishing, and possibly the eutrophication and agricultural and industrial pollution of Lake Erie. The blue walleye was distinguished from the yellow walleye by its bluish-gray (instead of yellowish) color, its larger eyes, small size, deeper and cooler habitat preference, etc.
To: Linn-Tarn Prints

2883 Otterson Drive

Ottawa, Ontario K1V 7B2, CANADA

Please mail $\$$

NAME:

ADDRESS:
Prints of the above drawing, $11 \times 17$ inches $(28 \times 43 \mathrm{~cm})$, black ink on acid-free dulcet paper, suitable for framing and gifts may be ordered with this form. prints(s) of the blue walleye at $\$ 25.00$ U.S. per print, for a total of herewith enclosed to:

PLeAse

PRINT OR

TYPE! 